\title{
Effect of Transfection and Passage Number of Ear Fibroblasts on In Vitro Development of Bovine Transgenic Nuclear Transfer Embryos
}

\author{
M.M.U. BHUIYAN ${ }^{1)}$, Jongki CHO ${ }^{1,2,3)}$, Goo JANG ${ }^{1)}$, Eulsoon PARK ${ }^{2)}$, Sungkeun $\mathrm{KANG}^{1)}$, Byeongchun $\mathrm{LEE}^{1) *}$ and \\ Woosuk HWANG ${ }^{1,2)}$ \\ ${ }^{1)}$ College of Veterinary Medicine, Seoul National University, Seoul 151-742, ${ }^{2}$ School of Agricultural Biotechnology, Seoul National \\ University, Suwon 441-744 and ${ }^{3)}$ College of Veterinary Medicine, Chungnam National University, Daejon 305-764, Korea
}

(Received 11 December 2002/Accepted 8 October 2003)

\begin{abstract}
The objective of this study was to determine if the transfection of human prourokinase (ProU) gene and passage number of transfected ear fibroblasts affected in vitro development of bovine transgenic nuclear transfer (NT) embryos. An expression plasmid for human ProU was constructed by inserting a bovine beta-casein promoter, a green fluorescent protein (GFP) marker and human ProU gene into a pcDNA3 plasmid and transfected into bovine ear fibroblasts using a lipid mediated method. Abattoir derived oocytes were enucleated at 18-20 hr post maturation and a single donor cell was transferred into the perivitelline space of a recipient oocyte. After fusion and activation, the couplets were cultured in modified synthetic oviductal fluid (mSOF) medium for $168 \mathrm{hr}$. In Experiment 1 , significantly lower rate in blastocysts formation $(10.3 \%)$ was observed in transfected donor cells at early passage than that in nontransfected counterparts $(22.1 \%, \mathrm{P}<0.05)$. In Experiment 2, development to blastocysts and GFP expression in blastocysts were not significantly different between early (3-7) and late (8-12) passage donor cells ( $10.3 \mathrm{vs.} 11.3 \%$ and $54.5 \mathrm{vs.} 41.7 \%$, respectively). This study indicates that in vitro development of bovine transgenic NT embryos is negatively influenced by transfection of human ProU gene into donor fibroblasts. However, passage number of transfected ear fibroblasts does not affect in vitro development of bovine transgenic NT embryos.
\end{abstract}

KEY WORDS: bovine ear fibroblast, in vitro development, passage number, transfection, transgenic nuclear transfer embryo.

Production of large volume of therapeutic proteins in milk of transgenic cows has a great value in the field of medicine [14]. Prourokinase (ProU) is the latest in a growing list of medicines being tested to dissolve clots in the brain and its main function is fibrinolysis [4]. To produce transgenic cows, somatic cell nuclear transfer (NT) technique is considered superior to other methods including pronuclear microinjection method $[15,20]$. For production of transgenic embryos by somatic cell NT, transfection and selection of donor cell lines are performed before nuclear transfer. There are reports that in vitro development of bovine transgenic NT embryos is negatively influenced by the transfection of donor cells [1, 28]. In contrast, Rohet al. [22] reported no difference in in vitro development of bovine transgenic NT embryos reconstructed with either enhanced green fluorescent protein (EGFP) gene transfected or nontransfected fetal fibroblasts. This difference in developmental rates of transgenic embryos among the studies may be due to differences in vector construction for a desired gene and transfection methods used. However, to our knowledge, there is no report on effect of transfection of adult bovine ear fibroblasts with human ProU gene on in vitro development of bovine NT embryos.

For efficient production of transgenic animals, it will be preferable to have stable incorporation of exogenous genes in donor cell lines. To obtain stable incorporation of exoge-

\footnotetext{
* Correspondence to: Lee, B., Laboratory of Theriogenology and Biotechnology, College of Veterinary Medicine, Seoul National University, San 56-1, Shillim-Dong, Kwanak-Gu, Seoul 151742 , Korea.
}

nous genes, donor cell lines should have potential to tolerate the insult of transfection and selection after prolonged culture with respect to culture period and cell passages. Moreover, prolonged culture of nuclear donor cells is essential for targeted genetic manipulation of donor cells such as "gene knock-out" [12]. There is report on difference in rate of in vitro development of bovine NT embryos between early and late passages ear fibroblasts as donor nuclei [12]. However, in vitro development of bovine transgenic NT embryos derived from transfected ear fibroblasts with respect to different passages has not yet been investigated. Therefore, the objective of this study was to determine whether the transfection of human ProU gene and passage number of transfected ear fibroblasts affected in vitro development of bovine transgenic NT embryos or not.

\section{MATERIALS AND METHODS}

Primary culture and transfection of ear fibroblasts: Ear tissues obtained from an adult Holstein cow (denoted as H213) were washed in Dulbecco's Phosfate Buffered Saline (DPBS; Life Technologies, Grand Island, NY) and minced with a surgical blade. The minced tissues were dissociated in Dulbecco's Modified Eagle Medium (DMEM; Life Technologies) supplemented with $0.25 \%(\mathrm{w} / \mathrm{v})$ trypsin and $1 \mathrm{mM}$ EDTA (Life Technologies) for $1 \mathrm{hr}$. Trypsinized cells were washed once by centrifugation at $300 \times \mathrm{g}$ for $10 \mathrm{~min}$ and subsequently seeded into $100 \mathrm{~mm}$ plastic culture dishes (Becton Dickinson, Franklin Lakes, NJ). Seeded cells were cultured for 6 to 8 days in DMEM supplemented with $10 \%$ 
(v/v) fetal bovine serum (FBS, Life Technologies), 1\% (v/v) non-essential amino acids (Life Technologies), and $100 \mathrm{iu} /$ $\mathrm{m} l$ penicillin and $0.1 \mathrm{mg} / \mathrm{m} l$ streptomycin (Sigma Chemical Co., St Louis) at $37^{\circ} \mathrm{C}$ in a humidified atmosphere of $5 \%$ $\mathrm{CO}_{2}$ and $95 \%$ air. After removal of unattached clumps of cells or explants, attached cells were further cultured until (100\%) confluency, and then subcultured at intervals of 5 to 7 days. An expression plasmid for human ProU (pbetaProU) was constructed by inserting a bovine beta-casein promoter (accession number: M55158.1), a green fluorescent protein (GFP) marker gene, and human ProU desired gene (accession number: X02419) into a pcDNA3 plasmid (Life Technologies). For transfection, ear fibroblasts were subcultured until 50-60\% confluency in a $35 \mathrm{~mm}$ culture dish and transfected with the plasmid using FuGene6® (Roche Diagnostics Corporation, Indianapolis, IN) according to the manufacturer's instruction. The transfected cells were cultured for at least 3-4 days in order to induce chromosomal integration of transgene and $100 \%$ confluency of the cell. Before nuclear transfer, donor cells were collected by trypsinization and resuspended in DPBS supplemented with $0.5 \%$ FBS. GFP-expressing cells were selected under ultraviolet (UV) light using a standard fluorescent isothiocyanate (FITC; excitation wave length: 450-490 nm; Bmode filter, Nikon, Japan) filter set and used as donor nuclei.

Nuclear transfer: Somatic cell nuclear transfer was performed according to the method described by Cho et al. [7]. Briefly, after in vitro maturation of slaughter house derived cumulus-oocyte complexes (COCs) for 18-20 hr in TCM199 (Life Technologies) supplemented with 10\% FBS, COCs were denuded by repeated pipetting with a narrow fire-polished pipette in handling medium (HEPES-buffered CR2aa medium) [23] supplemented with $0.1 \%$ hyaluronidase (Sigma). Micromanipulation of the denuded oocytes was performed in 3-4 $\mu l$ drops of handling medium supplemented with $10 \%$ FBS and $7.5 \mu \mathrm{g} / \mathrm{m} l$ cytochalasin B (Sigma) covered with mineral oil under differential interference contrast (DIC) microscopy (Nikon, Tokyo, Japan) equipped with micromanipulation system (Narishige, Tokyo, Japan). A slit was made in zona pellucida close to the first polar body with a glass needle and enucleation was performed by squeezing the oocyte to remove the first polar body with small volume of surrounding cytoplasm. For nuclear transfer, single GFP expressed cell was aspirated into the cell insertion pipette and inserted into the perivitelline space of the recipient oocyte through the same slit that was made during enucleation. Reconstructed couplets were electrically fused at $24 \mathrm{hr}$ post maturation by inducing 2 DC pulses of $1.75 \mathrm{kV} / \mathrm{cm}$ for $15 \mu \mathrm{sec}$ delivered by an electro-cell manipulator (BTX 2001, San Diego, U.S.A.) in calcium free mannitol medium. Activation of embryos was chemically performed by incubation in $5 \mu \mathrm{M}$ ionomycin (Sigma) for 4 min followed by post-activation in $2 \mathrm{mM} 6-$ dimethylaminopurine (Sigma) for $4 \mathrm{hr}$. Fusion rates were recorded under stereo microscope during washing after activation and confirmed by observing GFP expression in recip- ient cytoplasm under DIC microscopy equipped with FITC filter.

In vitro culture of reconstructed embryos: Five to 7 fused embryos were cultured in mSOF supplemented with $8 \mathrm{mg} /$ $\mathrm{m} l \mathrm{BSA}$ [8] at $39^{\circ} \mathrm{C}$ with $5 \% \mathrm{CO}_{2}, 5 \% \mathrm{O}_{2}$ and $90 \% \mathrm{~N}_{2}$ under humidified condition. The cleavage and blastocyst formation rates were recorded at $48 \mathrm{hr}$ and $168 \mathrm{hr}$ after activation, respectively. The GFP expression in blastocyst was determined under FITC filter. The blastocysts were considered as expressed blastocysts when GFP expression was observed in either whole or part of the blastocysts. When GFP expression was not observed in any part of the blastocysts, the blastocysts were considered as unexpressed blastocysts.

Experimental design: In Experiment 1, the effect of transfection of donor cells on in vitro development of transgenic NT embryos was determined. Transfected and nontransfected ear fibroblasts of same passage (3-7 passages) were used for comparison of embryo development. In Experiment 2, the effects of number of cell passages of transfected donor cells on in vitro development of NT embryos and GFP expression in blastocysts were examined. Transfected cells were cultured for at least 3-4 days and cell passages of transfected donor cells were divided into early (3-7) and late (8-12) passages groups before performing NT. The data for transfected donor cells in Experiment 1 was used as the data for early passage transfected cells in Experiment 2.

Statistical analysis: All data in each parameter were expressed as proportion and analyzed using a general linear model (PROC-GLM) in a SAS 8.12 program. Statistical significance was considered when the $\mathrm{P}$ value was less than 0.05 .

\section{RESULTS}

Experiment 1: Although the fusion rate was significantly higher $(73.8 \%)$ in reconstructed embryos derived from transfected donor cells than that in embryos derived from nontransfected counterparts $(62.8 \%, \mathrm{P}<0.05)$, there was no significant difference in cleavage rates of embryos reconstructed with either transfected or nontransfected donor cells (69.2 vs. $64.0 \%$, respectively; Table 1$)$. However, significantly lower number of reconstructed embryos developed to blastocysts stage after performing NT using transfected ear fibroblasts than that used nontransfected counterparts (10.3 vs. $22.1 \%$; $\mathrm{P}<0.05)$.

Experiment 2: The effect of passage number of transfected ear fibroblasts on development of transgenic NT embryos is shown in Table 2. There were no significant differences between embryos derived from either early (3-7) or late (8-12) passage donor cells in rates of fusion (73.8 vs. $65.0 \%)$, cleavage $(69.2$ vs. $56.6 \%)$, blastocysts formation (10.3 vs. $11.3 \%$ ) and GFP expression in blastocysts (54.5 vs. $41.7 \%$, respectively). In average, the GFP expression in blastocysts was $47.8 \%$ (11 out of 23). GFP expression was observed in embryos of all stages of development from 2cell to blastocysts with some mosaic expression. However, 
Table 1. Effect of transfection of ear fibroblasts on the development of bovine transgenic NT embryos

\begin{tabular}{lcccc}
\hline Type of donor cells & \multicolumn{4}{c}{ No. (\%) of embryos } \\
\cline { 2 - 5 } & Reconstructed & Fused & Cleaved $^{\text {a) }}$ & Blastocysts $^{\text {a) }}$ \\
\hline Nontransfected $(\mathrm{n}=5)$ & 137 & $86(62.8)^{\mathrm{b})}$ & $55(64.0)$ & $19(22.1)^{\mathrm{b})}$ \\
Transfected $(\mathrm{n}=5)$ & 145 & $107(73.8)^{\mathrm{c})}$ & $74(69.2)$ & $11(10.3)^{\mathrm{c}}$ \\
\hline
\end{tabular}

$\mathrm{n}=$ number of replicates in each group.

a) Percentages of cleaved embryos and blastocysts formation were calculated with respect to total fused embryos.

b) or, c) Values with different superscripts within same column differed significantly $(\mathrm{P}<0.05)$.

Table 2. Effect of number of passages of transfected ear fibroblasts on the development of bovine transgenic NT embryos

\begin{tabular}{lccccc}
\hline \multirow{2}{*}{$\begin{array}{l}\text { Number of } \\
\text { passages }\end{array}$} & \multicolumn{5}{c}{ No. (\%) of embryos } \\
\cline { 2 - 6 } & Reconstructed & Fused & Cleaved $^{\mathrm{a})}$ & Blastocysts & $\begin{array}{c}\text { Expressed } \\
\text { blastocysts }^{\mathrm{b})}\end{array}$ \\
\hline $3-7(\mathrm{n}=5)$ & 145 & $107(73.8)$ & $74(69.2)$ & $11(10.3)$ & $6(54.5)$ \\
$8-12(\mathrm{n}=5)$ & 163 & $106(65.0)$ & $60(56.6)$ & $12(11.3)$ & $5(41.7)$ \\
\hline
\end{tabular}

$\mathrm{n}=$ number of replicates in each group.

a) Percentages of cleaved embryos and blastocysts formation were calculated with respect to total fused embryos.

b) Percentages of expressed blastocysts were calculated with respect to total blastocysts formed.

the data on mosaic expression were not recorded.

\section{DISCUSSION}

Production of transgenic cloned cows to produce human ProU as a therapeutic protein has a great value in the field of medicine. In the present study, the effects of ProU gene transfection and passage number of transfected ear fibroblasts on in vitro development of bovine cloned embryos were evaluated. Although in vivo development of bovine transgenic NT embryos was not investigated by embryo transfer, the present study clearly demonstrated that bovine ear fibroblasts transfected with ProU gene yielded lower blastocysts development than nontransfected counterparts. However, passage number of transfected donor cells had no effect on in vitro development of transgenic embryos.

To produce transgenic animals by somatic cell NT technique, transfection and selection of cultured donor cells are important factors [27]. In the present study, in vitro development of bovine transgenic embryos was negatively affected by the transfection of a desired gene. This finding supports the earlier study in which lower in vitro development of NT embryos was obtained using bovine prochymosin gene transfected fetal fibroblasts [28]. Similarly, there are reports on lower development of transgenic NT embryos reconstructed with EGFP gene transfected donor cells in bovine [1] and porcine [16]. In contrast, there are reports to show no negative effect of EGFP gene transfection of fetal fibroblasts on development of transgenic embryos in bovine [22], goats [10] and pigs [11]. Although, the reason for lower rate of development of transgenic NT embryos in our study has not been confirmed, repeated exposure to UV light to visualize the transfected cells during nuclear transfer might contribute to this [1]. Furthermore, it is possible that introduction of a foreign gene may interfere with the proper reprogramming of bovine transgenic NT embryos [21].

Prolonged culture in terms of duration and passage number of transfected donor cells is essential for stable integration of transgene and selection of transfected cell lines before performing NT [27]. However, number of passages of transfected donor cells influenced the embryo development [2, 22, 24]. In the present study, ear fibroblasts up to 12 passages can be used for transfection of the ProU gene without any harmful effect on embryo development. On the contrary, development of bovine transgenic embryos was improved when reconstructed with granulosa cells with 15 passages [2], but was depressed when reconstructed with fetal fibroblasts with 17-32 passages [22]. This variation in embryo development in different studies might be due to using of different genes, donor cells and NT techniques [28].

For production of transgenic cells, various selection markers including antibiotics and GFP with different actions and advantages have been employed [5, 9]. Although antibiotics have successfully been used in generating transgenic cells, these induced cellular damage, senescence and chromosomal abnormality after long-term selection of somatic cells [9]. Since first introduced by Chalfie and colleagues in 1994, GFP is now emerged as a new selection marker because of its expression in a broad range of organism and no adverse biological effects [5]. In addition, the success in selecting and producing transgenic mice and pigs [6, 13, 19, 25] using GFP as a marker has paved the way for GFP in future transgenic experimentation. In this study, in order to produce transgenic NT 
embryos, we used a GFP gene as a selection marker and in average, $47.8 \%$ blastocysts expressed GFP under FITC filter with some mosaic expression. Similarly, GFP expression was not observed in all porcine transgenic NT embryos $[17,18]$, and mosaic expression of GFP gene was shown in the embryos [18]. In contrast, GFP expression was observed in all transgenic NT blastocysts of bovine [1, 3] and porcine [26] with no mosaic expression. The reason for mosaic expression of GFP gene observed in this study is not known at this moment. Since GFP gene was expressed in all fused embryos, the GFP gene might not be properly expressed during transition from maternal genome to the embryonic genome resulting in absence of GFP expression in some blastocysts.

In conclusion, the present study indicates that in vitro development of bovine transgenic NT embryos is negatively influenced by transfection of human ProU gene into the ear fibroblasts. However, passage number of transfected ear fibroblasts does not affect the in vitro development of bovine transgenic NT embryos.

ACKNOWLEDGMENTS. This study was supported by the grants from the Biogreen 21-1000520030100000. The authors acknowledge a graduate fellowship provided by the Ministry of Education through BK21 program.

\section{REFERENCES}

1. Arat, S., Gibbons, J., Rzucidlo, S. J., Respess, D. S. and Tumlin, M. 2002. In vitro development of bovine nuclear transfer embryos from transgenic clonal lines of adult and fetal fibroblast cells of the same genotype. Biol. Reprod. 66: 1768-1774.

2. Arat, S., Rzucidlo, S. J., Gibbons, J., Miyoshi, K. and Stice, S. L. 2001. Production of transgenic bovine embryos by transfer of transfected granulosa cells into enucleated oocytes. Mol. Reprod. Dev. 60: 20-26.

3. Bordignon, V., Keyston, R., Lazaris, A., Bilodeau, A. S., Pontes, J. H. F., Arnold, D., Fecteau, G., Keefer, C. and Smith L. C. 2003. Transgenic expression of green fluorescent protein and germ line transmission in cloned calves derived from in vitro-transfected somatic cells. Biol. Reprod. 68: 2013-2023.

4. Bugge, T. H., Flick, M. J., Danton, M. J., Daugherty, C. C., Romer, J., Dano, K., Carmeliet, P., Collen, D. and Degen, J. L. 1996. Urokinase type plasminogen activator is effective in fibrin clearance in the absence of its receptor or tissue-type plasminogen activator. Proc. Natl. Acad. Sci. 93: 5899-5904.

5. Chalfie, M., Tu, Y., Euskirchen, G., Ward, W. W. and Prasher, D. C. 1994. Green fluorescent protein as a marker for gene expression. Science 263: 802-805.

6. Chan, A. W. S. 1999. Transgenic animals: current and alternative strategies. Cloning 1: 25-46.

7. Cho, J. K., Lee, B. C., Park, J. I., Lim, J. M., Shin, S. J., Kim, K. Y., Lee, B. D. and Hwang, W. S. 2002. Development of bovine oocytes reconstructed with different donor somatic cells with or without serum starvation. Theriogenology 57: 18191828.

8. Choi, Y. H., Lee, B. C., Lim, J. M., Kang, S. K. and Hwang, W. S. 2002. Optimization of culture medium for cloned bovine embryos and its influence on pregnancy and delivery outcome. Theriogenology 58: 1187-1197.
9. Izumi, M. and Gilbert, D. M. 1999. Homogeneous tetracyclineregulatable gene expression in mammalian fibroblasts. J. Cell. Biochem. 76: 280-289.

10. Keefer, C. L., Baldassarre, H., Keyston, R., Wang, B., Bhatia, B., Bilodeau, A. S., Zhou, J. F., Leduc, M., Downey, B. R., Lazaris, A. and Karatzas, C. N. 2001. Generation of dwarf goat (Capra hircus) clones following nuclear transfer with transfected and nontransfected fetal fibroblasts and in vitro-derived oocytes. Biol. Reprod. 64: 849-856.

11. Koo, D. B., Kang, Y. K., Choi, Y. H., Park, J. S., Kim, H. N., Kim, T., Lee, K. K. and Han, Y. M. 2001. Developmental potential and transgene expression of porcine nuclear transfer embryos using somatic cells. Mol. Reprod. Dev. 58: 15-21.

12. Kubota, C., Yamakuchi, H., Todoroki, J., Mizoshita, K., Tabara, N. and Barber, M. 2000. Six cloned calves produced from adult fibroblast cells after long-term culture. Proc. Natl. Acad. Sci. 97: 990-995.

13. Lai, L., Park, K. W., Cheong, H. T., Kuhholzer, B., Samuel, M., Bonk, A., Im, G. S., Rieke, A., Day, B. N., Murphy, C. N., Carter, D. B. and Prather, R. S. 2002. Transgenic pig expressing the enhanced green fluorescent protein produced by nuclear transfer using colchicine-treated fibroblasts as donor cells. Mol. Reprod. Dev. 62: 300-306.

14. Lubon, H., Paleyanda, R. K., Velander, W. H. and Drohan, W. N. 1996. Blood proteins from transgenic animal bioreactors. Transfusion Med. Rev. 10: 131-143.

15. Niemann, H. and Kues, W. A. 2000. Transgenic livestock: premises and promises. Anim. Reprod. Sci. 60-61: 277-293.

16. Park, K. W., Cheong, H. T., Lai, L., Im, G. S., Kuhholzer, B., Bonk, A., Samuel, M., Rieke, A., Day, B. N., Murphy, C. N., Carter, D. B. and Prather, R. S. 2001. Production of nuclear transfer-derived swine that express the enhanced green fluorescent protein. Anim. Biotechnol. 12: 173-181.

17. Park, K. W., Kuhholzer, B., Lai, L., Machaty, Z., Sun, Q. Y., Day, B. N. and Prather, R. S. 2001. Development and expression of the green fluorescent protein in porcine embryos derived from nuclear transfer of transgenic granulosa-derived cells. Anim. Reprod. Sci. 68: 111-120.

18. Park, K. W., Lai, L., Cheong, H. T., Cabot, R., Sun, Q. Y., Wu, G., Rucker, E. B., Durtschi, D., Bonk, A., Samuel, M., Rieke, A., Day, B. N., Murphy, C. N., Carter, D. B. and Prather, R. S. 2002. Mosaic gene expression in nuclear transfer-derived embryos and the production of cloned transgenic pigs from earderived fibroblasts. Biol. Reprod. 66: 1001-1005.

19. Park, K.W., Lai, L., Cheong, H. T., Im, G. S., Sun, Q. Y., Wu, G., Day, B. N. and Prather, R. S. 2001. Developmental potential of porcine nuclear transfer embryos derived from transgenic fetal fibroblasts infected with the gene for the green fluorescent protein: comparison of different fusion/activation conditions. Biol. Reprod. 65: 1681-1685.

20. Piedrahita, J. A. 2000. Targeted modification of the domestic animal genome. Theriogenology 53: 105-116.

21. Rideout III, W. M., Eggan, K. and Jaenisch, R. 2001. Nuclear cloning and epigenetic reprogramming of the genome. Science 293: 1093-1098.

22. Roh, S., Shim, H., Hwang, W. S. and Yoon, J. T. 2000. In vitro development of green fluorescent protein (GFP) transgenic bovine embryos after nuclear transfer using different cell cycles and passages of fetal fibroblasts. Reprod. Fertil. Dev. 12: $1-6$.

23. Rosenkrans, C. F. Jr., Zeng, G. Q., McNamara, G. T., Schoff, P. K. and First, N. L. 1993. Development of bovine embryos in vitro as affected by energy substrates. Biol. Reprod. 49: 459- 
462.

24. Schnieke, A. E., Kind, A. J., Ritchie, W. A., Mycock, K., Scott, A. R., Ritchie, M., Wilmut, I., Colman, A. and Campbell, K. H. S. 1997. Human factor IX transgenic sheep produced by transfer of nuclei from transfected fetal fibroblasts. Science $\mathbf{2 7 8}$ : 2130-2133.

25. Takada, T., Iida, K., Awaji, T., Itoh, K., Takahashi, R., Shibui, A., Yoshida, K., Sugano, S. and Tsujimoto, G. 1997. Selective production of transgenic mice using green fluorescent protein as a marker. Nat. Biotechnol. 15: 458-461.

26. Uhm, S. J., Kim, N. H., Kim, T., Chung, H. M., Chung, K. H., Lee, H. T. and Chung, K. S. 2000. Expression of enhanced green fluorescent protein (EGFP) and neomycin resistant $\left(\mathrm{Neo}^{\mathrm{R}}\right)$ genes in porcine embryos following nuclear transfer with porcine fetal fibroblasts transfected by retrovirus vector. Mol. Reprod. Dev. 57: 331-337.

27. Westhusin, M. E., Long, C. R., Shin, T., Hill, J. R., Looney, C. R., Pryor, G. H. and Piedrahita, J. A. 2001. Cloning to reproduce desired genotypes. Theriogenology 55: 35-49.

28. Zakhartchenko, V., Mueller, S., Alberio, R., Schernthaner, W., Stojkovic, M., Wenigerkind, H., Wanke, R., Lassnig, C., Mueller, M., Wolf, E. and Brem, G. 2001. Nuclear transfer in cattle with non-transfected and transfected fetal or cloned transgenic fetal and postnatal fibroblasts. Mol. Reprod. Dev. 60: 362-369. 